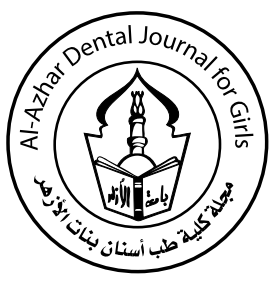

\title{
Effect of Childhood Malnutrition on Salivary Flow and pH
}

\author{
Doaa S. Hashem ${ }^{(1)}$, Samy Y. El-Bayoumy ${ }^{(2)}$, Wafaa A. Fahmy ${ }^{(3)}$ and Magda A. EI Malt $^{(4)}$
}

Codex : 08/1604

dentaljournal.forgirls@yahoo.com

\section{INTRODUCTION}

Malnutrition essentially means "bad nourishment". It concerns not enough as well as too much food, the wrong types of food, and the body's response to a wide range of infections that result in malabsorption of nutrients or the ability to use nutrients properly to maintain health ${ }^{(1,2)}$.

\begin{abstract}
The aim of the present study was to assess the effect of childhood malnutrition on salivary flow rate and $\mathrm{pH}$. Four hundred children between 3-12 years were selected for this study. The children were divided into two main groups according to their nutrition status, Group (A): two hundred children representing the malnourished children, Group (B): two hundred children representing the control group. Within Group (A) Children were further divided into 2 subgroups, subgroup (1): one hundred stunted children and subgroup (2): one hundred underweight children. Every child was subjected to unstimulated and stimulated saliva flow and $\mathrm{pH}$ measurements and caries status evaluation using dmf index for primary and DMF index for permanent teeth. The results showed undernutrition (underweight) and stunting reduced the secretion rate of stimulated saliva and no effect on unstimulated salivary flow rate or saliva $\mathrm{pH}$. Moreover, undernutrition (underweight) increased the caries index of primary teeth, while stunting increased the caries index of permanent teeth. It was concluded that malnutrition causes enamel hypoplasia, salivary gland hypofunction and saliva compositional changes and these might be the mechanisms through which malnutrition associated with caries.
\end{abstract}

Malnutrition Salivary Flow
Malnutritic $\mathrm{pH}$

\section{KEYWORDS}

1. B.D.S, Faculty of Oral and Dental Medicine, Cairo University (2007)

2. Professor and Head of Department of Pedodontics and Dental Public Health. Faculty of Dental Medicine (Boys' branch), Al Azhar University.

3. Professor of Public Health and Nutrition. National Nutrition Institute, Cairo, Egypt.

4. Lecturer, Pediatric Dentistry and Public Health Department. Faculty of Dental Medicine (Girls' branch), Al Azhar University. 
Wasting and stunting are very different forms of malnutrition. Stunting is chronic and its causative factors are poorly understood. Wasting results from an acute shortage of food, is reversible with refeeding, and has a relatively high mortality rate ${ }^{(3)}$.

Saliva has one of the most difficult roles to perform in the body. It must facilitate the taste and detection of foods nutritious to the body but also defend the mucosa from infection by the ever-present microbiota present in the mouth. It achieves these roles by having a complex composition and versatile physical properties ${ }^{(4)}$.

Hypofunctioning of the salivary glands has been reported with PEM, which results in a decreased salivary flow rate, a decreased buffering capacity, and decreased salivary constituents, particularly proteins .PEM and vitamin A deficiency are associated with salivary gland atrophy, which subsequently reduces the defense capacity of the oral cavity against infection and its ability to buffer the plaque $\operatorname{acids}^{(5)}$.

PEM can be correlated with the host factors, which are associated with the development of caries, especially tooth defects and the salivary system. The salivary flow rates are related to caries directly through oral clearance and in terms of the buffering capacity and the antimicrobial components ${ }^{(6)}$.

\section{MATERIALS AND METHODS}

This study was carried out in the National Nutrition Institute (NNI) Ministry of Health: Cairo. Four hundred children between 3-12 years were selected for this study. The children were divided into two main groups according to their nutrition status, Group (A): two hundred children representing the malnourished children, they were further divided into 2 subgroups, subgroup (1): one hundred children attending the pediatric malnutrition clinic and subgroup (2): one hundred children attending the pediatric stunting clinic, Group (B): two hundred children representing the control group, selected from the children who were apparently healthy and with normal body weight, who accompanied the malnourished children attending the pediatric malnutrition outpatient clinic of National Nutrition Institute (NNI). This group matched with the cases group in sexes and age range.

Every child was subjected to anthropometric measures: World Health Organization (WHO) standard scale provided by NNI for normal weight and height for boys and girls according to their age was used.

In order to test the unstimulated saliva flow rate, the child was instructed to sit in an upright position and to incline his head forward so the produced saliva could be collected in the floor of the mouth and then flow over the lower lip into a measure using a funnel for 15 minute. For stimulated saliva collection, the child was instructed to chew a sugar free gum (Trident sugar free gum with mint flavor) for 3 minutes during which the saliva being spat out at short intervals into a measure. The samples were then immediately placed on ice to minimize bacterial degradation of salivary proteins until further processing. The total amount of saliva collected, excluding the foam that was formed during collection process, was recorded.

The determination of $\mathrm{pH}$ for unstimulated and stimulated saliva was assessed using $\mathrm{pH}$ meter. Caries status evaluation using $\mathrm{dmf}$ index for primary and DMF index for permanent teeth was done for all children.

\section{RESULTS}

\section{Height}

Normal group had statistically significantly higher secretion rate of stimulated saliva than stunted group (table 1).No significance difference was found in the mean of unstimulated saliva flow rate or saliva $\mathrm{pH}$. However, the stunted group had statistically significantly higher DMF than the normal group (table 2) 


\section{Weight}

Normal group had statistically significantly higher secretion rate of stimulated saliva than underweight group (Table 3). No significance differ- ence was found in the mean of unstimulated saliva flow rate or saliva $\mathrm{pH}$. However, the underweight group had statistically significantly higher $\mathrm{dmf}$ than the normal group (table 4).

Table 1. Range, mean $\pm S D$ of stimulated salivary flow rates in relation to height in the studied groups

\begin{tabular}{|c|c|c|c|c|c|c|}
\hline \multirow{3}{*}{$\begin{array}{c}\text { HEIGHT } \\
\text { Normal }\end{array}$} & \multicolumn{4}{|c|}{ S.S.F.R } & \multicolumn{2}{|c|}{ ANOVA } \\
\hline & \multicolumn{2}{|c|}{ Range } & \multirow{2}{*}{$\begin{array}{c}\text { Mean } \\
1.094 \pm\end{array}$} & \multirow{2}{*}{$\begin{array}{l}\text { SD } \\
0.655\end{array}$} & $\mathbf{F}$ & P-value \\
\hline & 0.160 & 4.000 & & & \multirow{3}{*}{8.771} & \multirow{3}{*}{0.000} \\
\hline Stunted & 0.160 & 2.760 & $0.884 \pm$ & 0.554 & & \\
\hline Tall & 0.230 & 0.700 & $0.465 \pm$ & 0.251 & & \\
\hline \multicolumn{7}{|c|}{ Turkey's test } \\
\hline \multicolumn{3}{|c|}{ Normal\& Stunted } & \multicolumn{2}{|c|}{ Normal\& Tall } & \multicolumn{2}{|c|}{ Stunted\& Tall } \\
\hline \multicolumn{2}{|c|}{0.002} & & \multicolumn{2}{|l|}{0.012} & \multicolumn{2}{|c|}{0.139} \\
\hline
\end{tabular}

Table 2. Range, mean \pm SD of caries index of the permanent teeth in relation to height in the studied groups

\begin{tabular}{|c|c|c|c|c|c|c|}
\hline \multirow{3}{*}{$\begin{array}{l}\text { HEIGHT } \\
\text { Normal }\end{array}$} & \multicolumn{4}{|c|}{ DMF1 } & \multicolumn{2}{|c|}{ ANOVA } \\
\hline & \multicolumn{2}{|r|}{ Range } & \multirow{2}{*}{$\begin{array}{cc}\text { Mean } & \pm \\
0.867 & \pm\end{array}$} & \multirow{2}{*}{$\frac{\text { SD }}{1.525}$} & $\mathbf{F}$ & P-value \\
\hline & 0.000 & $: \quad 6.000$ & & & \multirow{3}{*}{11.889} & \multirow{3}{*}{0.000} \\
\hline Stunted & 0.000 & $: \quad 6.000$ & $1.739 \pm$ & 1.809 & & \\
\hline Tall & 0.000 & $: \quad 0.000$ & $0.000 \pm$ & 0.000 & & \\
\hline \multicolumn{7}{|c|}{ Turkey's test } \\
\hline \multicolumn{3}{|c|}{ Normal\& stunted } & \multicolumn{2}{|l|}{ Normal\& tall } & \multicolumn{2}{|c|}{ Stunted \& Tall } \\
\hline \multicolumn{3}{|c|}{$<0.001 *$} & \multicolumn{2}{|l|}{0.284} & \multicolumn{2}{|c|}{0.009} \\
\hline
\end{tabular}

Table 3. Range, mean \pm SD of stimulated salivary flow rate in relation to weight in the studied groups

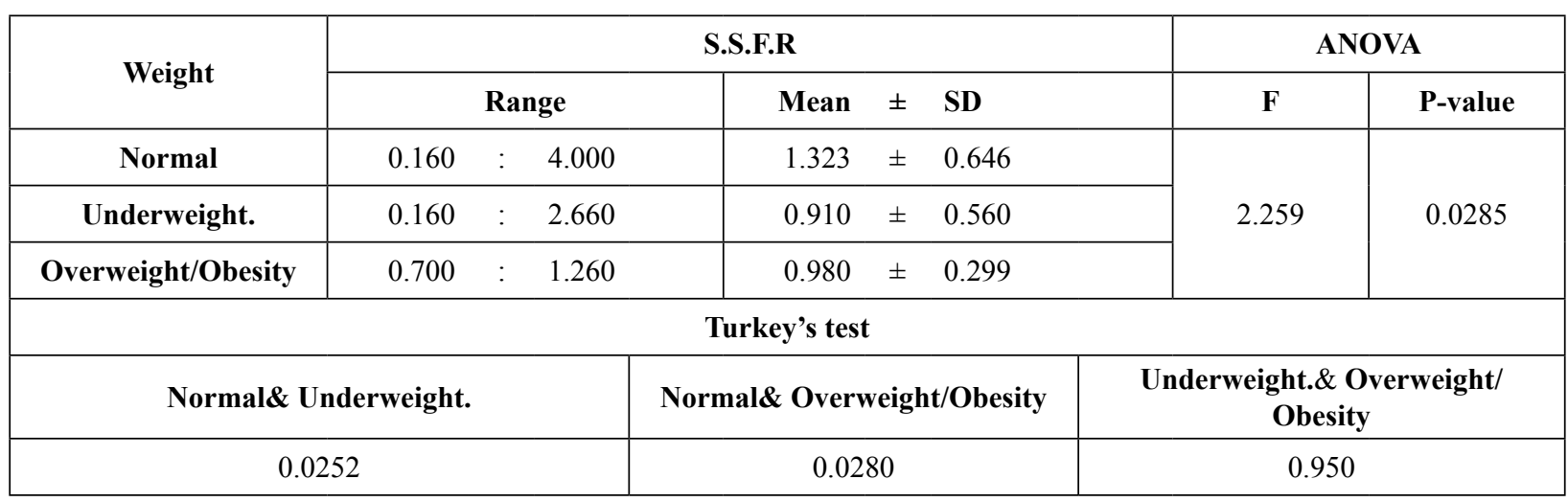


Table 4. Range, mean $\pm S D$ of caries index of primary teeth in relation to weight in the studied groups

\begin{tabular}{|c|c|c|c|c|c|}
\hline \multirow{2}{*}{ Weight } & \multicolumn{4}{|c|}{ dmf2 } & \multicolumn{2}{c|}{ T-test } \\
\cline { 2 - 6 } & \multicolumn{2}{|c|}{ Range } & Mean \pm SD & t & P-value \\
\hline Normal & $0.000: 11.000$ & $3.357 \quad \pm 3.244$ & \multirow{2}{*}{0.008} \\
\cline { 1 - 5 } Underweight & $0.000: 12.000$ & $3.463 \quad \pm 2.829$ & & \\
\hline
\end{tabular}

\section{DISCUSSION}

Different studies used different methods for collecting whole saliva such as draining, spitting, suction and swab methods ${ }^{(7)}$. In this study, we use the draining and spitting methods as it was found that the suction and swab methods induced certain degree of stimulation and variability. In the present study, it was noticed a significant association $(\mathrm{p}<0.05)$ in mean of stimulated salivary flow rate in studied groups. The higher mean stimulated salivary flow rate was found in the children of normal height group and normal weight group comparing to the mean of the stimulated salivary flow rate of stunted group and underweight group

Regarding unstimulated salivary flow rate, the result presents no significance difference in the mean of unstimulated salivary flow rate in the studied groups. This may be due to changes in parotid gland weight and a decreased $\beta$ adrenoceptor density following protein energy malnutrition and the parotid gland contributing more than $50 \%$ of total stimulated salivary secretions and contributing only $20 \%$ of unstimulated salivary secretions. This result agrees with a study which was conducted among 84 malnourished and 89 well-nourished children aged 5 years of Baghdad city, revealed that mean value of stimulated salivary flow rate was found to be highly significantly lower among malnourished than wellnourished $^{(8)}$.

In the current study, it was noticed no significant difference in the mean of $\mathrm{pH}$ of both unstimulated and stimulated saliva in the studied groups. This re- sult agrees with a study of salivary flow and dental caries in Indian children suffering from chronic malnutrition revealed that no significant association in mean of $\mathrm{pH}$ between Indian malnourished group and Swedish age-and sex matched control group ${ }^{(9)}$.

In the present study it was noticed a significant association $(\mathrm{p}<0.001)$ in mean of DMF between normal height group and stunted group with higher mean DMF was found in stunted group. This may be due to that stunting delays the eruption of the deciduous teeth and accelerate the eruption of the permanent teeth. This result agrees with a longitudinal study to assess the individual and grouped influence of host-related factors on dental caries experience in permanent dentition of 7-9 year-old children, demonstrated that stunting being one of the risk factors of dental caries in permanent dentition ${ }^{(10)}$.

In the present study it was noticed a significant association in mean of $\mathrm{dmf}$ between normal weight children group and underweight children with higher mean dmf in underweight group. This may be due to that undernutrition delays the deciduous teeth exfoliation and delay the permanent teeth eruption so make number of remaining deciduous teeth higher than normal, number of permanent teeth lower than normal. This study agrees with a study to assess whether dental caries was related to nutritional status in preschool urban Brazilian children aged 1259 months, revealed that underweight children and those with adverse socio-economic conditions were more likely to have caries experience ${ }^{(11)}$. 


\section{CONCLUSION}

A cross-sectional relationship is present between being underweight or stunt and the stimulated salivary flow rate and dental caries.Undernutrition (underweight) and stunting cause decreased stimulated salivary flow rate and no effect on unstimulated salivary flow rate or saliva $\mathrm{pH}$.

Undernutrition (underweight) causes increased caries index of primary teeth. Stunting causes increased caries index of permanent teeth. Malnutrition causes enamel hypoplasia, salivary gland hypofunction and saliva compositional changes and these might be the mechanisms through which malnutrition associated with caries.

\section{REFERENCES}

1. WHO: Turning the tide of malnutrition: responding to the challenge of the 21 st century. Geneva: WHO, 2000 (WHO/ NHD/00.7), 2000.

2. FAO: The state of food insecurity in the world (FAO, Rome), 2000.

3. London School of Hygiene and Tropical Medicine: The use of epidemiological tools in conflict-affected populations. ((http://conflict.lshtm.ac.uk/page_121.htm), 2009.
4. Carpenter G.H.: The secretion, components, and properties of saliva. Annu Rev Food Sci Technol. 4:267-76, 2013.

5. Psoter W.J., Spielman A.L., Gebrian B., Rudolph S.J. and Katz R.V.: Effect of childhood malnutrition on salivary flow and pH. Arch Oral Biol. 53(3):231-37, 2008.

6. Psoter W.J., Reid B.C. and Katz R.V.: Malnutrition and Dental Caries: A Review of the Literature. Caries Res. 39(6):441-47, 2005.

7. Navazesh M.: saliva. Ann N Y Acad Sci. Sep 20; 694:72-7, 1993.

8. Hassan Z.S. and Diab B.S.: The effect of nutritional status on dental caries in relation to salivary flow rate, $\mathrm{pH}$, inorganic phosphorus, calcium, copper and lead among five years old kindergarten children. J Bagh College Dentistry Vol. 22(3), 2010.

9. Johansson I., Saellström A.K., Rajan B.Pand Parameswaran A.: Salivary flow and dental caries in Indian children suffering from chronic malnutrition. Caries Res.26 (1):3843, 1992.

10. Delgado-Angulo E.K. and Bernabé E.: Influence of hostrelated risk indicators on dental caries in permanent dentition. Acta Odontol Latinoam. 19(2):85-92, 2006.

11. Oliveira L.B., Sheiham A. and Bönecker M.: Exploring the association of dental caries with social factors and nutritional status in Brazilian preschool children. Eur J Oral Sci. Feb; 116(1):37-43, 2008. 